Hispania, LXV/3, núm. 221 (2005)

\title{
ESPACIOS, FORMAS Y MANIFESTACIONES MODERNAS DE LA CULTURA ESCRITA: ESPAÑA Y PORTUGAL (SIGLOS XVI-XIX)
}

\section{INTRODUCCIÓN}

La madurez historiográfica y los generosos resultados alcanzados en las últimas décadas por los estudios sobre de la cultura escrita en general, y en España y Portugal en particular, han sido posibles gracias a una sólida revisión de conceptos y experiencias, que probablemente no hubieran tenido los mismos efectos si no hubiera habido en su propia base un entusiasta y formidable incremento del interés por su estudio.

En este inicio de siglo, afortunadamente, empieza a ser superfluo y hasta redundante el escribir enjundiosas glorificaciones para explicar la importancia de los estudios sobre cultura escrita, y en general de las múltiples funcionalidades que de ella pudieran exponerse sobre los análisis del libro, la lectura o la escritura. En cualquiera de ellos, el avance de la investigación y el balance productivo experimentado en el haber particular de los dos países ibéricos permite ya hablar de objetivos y procedimientos perfectamente definidos y consolidados.

Una novedad que, tal vez, apenas hace tres décadas, a la hora de proponer un monográfico como el que aquí presentamos no hubiera tenido sentido, o al menos hubiera sido calificado, tal vez con acierto, de aventurado. $Y$ es en este momento - en un avance en la declaración de intenciones perseguidas con este conjunto de artículos - cuando debemos y podemos hablar de un camino principal y de un objetivo único: penetrar en la dirección de normalidad en los valores reconocidos que definen las directrices de la nueva historia cultural de lo social. Finalmente, sin pretender dejar resuelta ninguna cuestión establecida, y desde la plena libertad en la elección de los temas, se trata de completar una propuesta de fundamentación de los «espacios, formas y manifestaciones» de la cultura escrita como puesta en valor de los resultados de la presente actividad historiográfica peninsular.

Unas expectaciones de regularidad historiográfica, en efecto, que constituyen el siempre oportuno reconocimiento a la labor desarrollada por un presente y un futuro en formación de hasta ahora consolidados investigadores de la talla

Hispania, LXV/3, núm. 221 (2005) 809-812 
de Fernando Bouza, Antonio Castillo, José Luis Gonzalo, Manuel Lucena Giraldo, Rita Marquilhas y Cristina Albino o Manuel Peña, junto al autor de esta presentación que aprovecha la oportunidad para agradecer a todos ellos, amigos y colegas, sus valiosas y desinteresadas colaboraciones.

A lo largo del presente Informe, no le será difícil descubrir al lector cómo las permanencias y realidades empiezan a completar el amplio espacio que hasta hace poco ocupaban sólo las proposiciones, y, a su vez, cómo muchas de las grandes cuestiones de estudio de la historia de la cultura escrita van rematándose, divisándose cada vez con mayor nitidez sus hasta ahora bastante opacos contornos, a pesar de que aún quede mucho por profundizar.

Como contribución a estos objetivos se ha diseñado, deliberadamente, un monográfico abierto, susceptible de acometer en su fusión algunas de las complejidades y proximidades que ofrece el fenómeno que rodea al mundo del libro, de la lectura y de la escritura. En cualquier caso, los siete artículos aquí reunidos, a partir de una amplia pluralidad de miras y desde una tenue continuidad cronológica, manifiestan importantes novedades teóricas y un variado abanico metodológico perfectamente aparejadas a la naturaleza e importancia de la documentación utilizada. Una muestra más de los rasgos del nuevo enfoque aludido, pero sin dejar de manifestar los tonos y graduaciones propios de los casos español y luso, y del desahogado auge de la investigación surgida sobre las muchas aberturas que sobre el tema quedaron sin cerrar al comenzar los años ochenta y noventa.

Desde un planteamiento estrictamente cronológico el presente Informe se inicia con un estudio de José Luis Gonzalo Sánchez-Molero dedicado a los libros del secretario de Felipe II, Mateo Vázquez de Leca. A través de una documentación inédita conservada en el archivo del Instituto de Valencia de Don Juan (Madrid), Gonzalo se interesa, previamente, por los métodos de trabajo del secretario Vázquez, los libros que compusieron su magnífica biblioteca de referencia y los diferentes materiales que ocuparon su escritorio, para posteriormente preguntarse y dar respuesta a la «polémica» decisión de Felipe II de nombrarle su secretario personal en 1573 .

Continua con el trabajo de Antonio Castillo Gómez que, basándose en algunas observaciones previas acerca de los discursos tocantes a la materia epistolar, ahonda en los significados y funciones de este tipo de escritura durante los siglos XVI y XVII. Propone un esmerado análisis de las características materiales de los testimonios epistolares. Distingue entre cartas y billetes, precisando la constitución formal de ambas tipologías, y diferencia las relaciones entre la condición social de las personas y la propia producción escrita: desde las gentes de letras hasta los escribientes más inexpertos.

Ceñido en ese mismo periodo altomoderno, el autor de estas líneas se ocupa en su artículo de relacionar el mundo de la literatura histórica con la concreta situación lectora de la sociedad madrileña. Una amplio espacio de tiempo (1550-1650) en el que los recursos de la producción y distribución impresa madrileña, a pesar de sus dificultades estructurales, favorecieron, entre otros 
intereses editoriales, disciplinas de conocimiento como la historia que pasó a convertirse en una literatura probativa y de estrategia política, todo ello en un tiempo en donde se supo apostar en la preparación de un proyecto comunitario de recuperación de la conciencia nacional.

Los artículos de Manuel Peña y Fernando Bouza se inscriben en la centuria del seiscientos. En el primero, dedicado a El Quijote (en este feliz año de su centenario), se nos ofrece un sugerente texto lleno de matices acerca del estructural desconcierto habido entre algunos estudiosos a la hora de calificar la postura de Cervantes ante los conceptos de libertad o represión. Una actitud desprendida de determinados comentarios del autor sobre las maneras de censurar. La disimulada contradicción de mensajes — según Peña - en los distintos pasajes de la obra, demuestra, en esencia, la perplejidad de un autor seducido por la ambivalencia de la duda, encerrado en la creativa tesitura de optar por la trasgresión de los límites o por la necesidad de las normas. El escrutinio cervantino -en ese sentido- es único: en él se remedan las paradójicas prácticas y singulares criterios censoriales de la época. En el segundo, por su parte, Fernando Bouza, tomando como fondo de observación las necesidades de la imprenta hispana del siglo XVII, y a través de una documentación original presentada en 1685 ante el Consejo de Castilla, nos propone un sugerente trabajo en donde se profundiza sobre la propuesta hecha por el artífice borgoñón Pedro de Disses de fabricar en Madrid moldes, punzones y matrices de imprenta originales. Una iniciativa presentada como un mecanismo de creación, tal vez sólo como una aspiración por parte de autores y tipógrafos para llegar a la construcción colectiva de la memoria de nación.

Los dos trabajos restantes se refieren al siglo XVIII y primeras décadas del XIX. Un tiempo cíclico en el que muchas de las tendencias apuntadas experimentaron avances o al menos significativas derivaciones hacia nuevas formas y manifestaciones que trataban de acoplarse al mismo tiempo en la costumbre y la novedad. En el primero de ellos, Manuel Lucena Giraldo examina la singular tarea de la censura como herramienta de creación historiográfica y mecanismo de definición de un determinado rango en la república de la letras. Desde la idea de que la historiografía expresaba una voluntad de representación del pasado, y de que la censura constituía, al menos en teoría, su negación, el autor se pregunta si el terreno intermedio entre ambas quedaba tan claramente delimitado como tradicionalmente se ha venido proponiendo. De manera simultánea, se plantea conocer y al mismo tiempo revisar el proceso por el que los escritos históricos pretendían difundir modelos y representaciones sociales. En otras palabras, dar la batalla del conocimiento a favor de la educación y en contra de la superstición y la barbarie popular.

Con el último de los artículos llegamos hasta las primeras décadas del Portugal del siglo XIX con la sugerente aportación de las profesoras Rita Marquilhas y Cristina Albino. Un estudio circunscrito en los sombríos y convulsos años marcados por la crisis de Antiguo Régimen (1807-1834) en donde los desajustes políticos, sociales e ideológicos favorecieron el germen de numerosos 
episodios criminales protagonizados por el fenómeno del bandidaje portugués. Se analiza en particular una modalidad aparentemente desembarazada y «elegante» de extorsionar dinero y ajustar cuentas a través de la escritura de «cartas amenazantes» o «cartas aterradoras» (términos utilizados en los procesos judiciales) enviadas desde prisión a sus víctimas utilizando como firma el nombre de salteadores y criminales famosos de la época. A través de casi un centenar de esas cartas se recrea un minucioso análisis histórico lingüístico así como un estudio de las particulares prácticas comunicativas y de los estereotipos epistolográficos más utilizados en aquel tiempo.

En definitiva, los modelos e ideas que se muestran a continuación, desde mi particular punto de vista, transfieren con garantía de éxito la renovada imagen de un edificio multiforme y bien relacionado. Un nuevo diseño de propuestas de diferente naturaleza muy acorde con los intereses culturales e históricos de la diversas comunidades letradas que se establecieron en tierras de la península Ibérica durante la Edad Moderna. En cualquier caso, una buena ocasión para felicitarnos y felicitar la generosa acogida por parte del director y el consejo de redacción de la revista Hispania, e igualmente una inmejorable oportunidad para esperar, como corresponde al tema elegido, la última palabra de los lectores. 